\title{
Low asymmetry of primary moult in Dunlins Calidris alpina alpina migrating to wintering grounds
}

\author{
Włodzimierz Meissner ${ }^{1}\left[\right.$ Grzegorz Zaniewicz $^{1} \cdot$ Andrzej Kośmicki $^{2} \cdot$ Anna Włodarczak-Komosińska $^{3}$
}

Received: 1 February 2018 / Revised: 10 October 2018 / Accepted: 24 October 2018 / Published online: 3 November 2018

(c) The Author(s) 2018

\begin{abstract}
The Dunlin is one of very few wader species that moults primaries when migrating to its wintering grounds. In our study, a total of $68.2 \%$ of immatures and $26.6 \%$ of adults underwent their primary moult when passing through the southern Baltic in autumn. More than $30 \%$ of moulting birds revealed differences in moult scores of left and right wings. However, $13 \%$ of Dunlins showed differences between the left and right wing not greater than $1 \%$, and $50 \%$ of individuals showed differences between the two wings that were lower than $3 \%$ of the total mass of all primaries. The probability of asymmetry during the primary moult increased over time and decreased with the advancement of the primary moult. Sex and age of birds had no significant effect on the occurrence of moult asymmetry. The level of asymmetry in the primary moult increased in the following days of autumn migration and with the advancement of the primary moult. The mean index of primary moult asymmetry (the absolute value of the difference in moult advancement between the left and right wing) was lower in immature Dunlins than in adults, and in females compared to males. Hence, sex (males) and age classes (adults) that spend a longer time on the breeding grounds revealed a higher index of primary moult asymmetry, most probably as a result of higher levels of physiological stress. However, the low proportion of birds showing large asymmetry suggests that this is strongly constrained by selection for aerodynamic efficiency, as asymmetry in primaries affects aerodynamic stability, take-off costs, manoeuvrability and agility in birds with flapping flight.
\end{abstract}

Keywords Wing asymmetry $\cdot$ Fluctuating asymmetry $\cdot$ Stress $\cdot$ Waders $\cdot$ Aerodynamic efficiency

\section{Zusammenfassung}

Geringe Asymmetrie in der Handschwingenmauser von Alpenstrandläufern Calidris alpina alpina auf dem Zug ins Winterquartier

Der Alpenstrandläufer ist eine von sehr wenigen Limikolenarten, die ihre Handschwingen auf dem Zug ins Winterquartier mausern. In unserer Studie mauserten insgesamt 68,2\% der Immaturen und 26,6\% der Altvögel ihre Handschwingen, während sie im Herbst durch das südliche Baltikum zogen. Über 30\% der mausernden Vögel zeigten Unterschiede in den Mauserwerten der beiden Flügel. Bei 13\% der Alpenstrandläufer waren die Unterschiede jedoch nicht größer als 1\% und bei 50\% der Individuen geringer als 3\% des Gesamtgewichts aller Handschwingen. Die Wahrscheinlichkeit einer asymmetrischen Handschwingenmauser nahm über die Zugzeit zu und mit dem Fortschreiten der Mauser ab. Geschlecht und Alter der Tiere hatten keinen signifikanten Einfluss auf das Auftreten von Mauserasymmetrie. Das Ausmaß der Asymmetrie in der Handschwingenmauser nahm in den folgenden Tagen des Herbstzuges und mit dem Fortschreiten der Handschwingenmauser zu. Der mittlere Index der Handschwingenmauser-Asymmetrie (die absolute Differenz im Fortschreiten der Mauser zwischen linkem und rechtem Flügel) war bei immaturen Alpenstrandläufern geringer als bei Altvögeln und bei Weibchen geringer als bei Männchen. Daher wies das Geschlecht (Männchen) bzw. die Altersklasse (Altvögel), die länger im Brutgebiet blieb, einen höheren Index der Handschwingenmauser-Asymmetrie auf, wahrscheinlich aufgrund von stärkerem physiologischen Stress. Insgesamt deutet der geringe Anteil von Vögeln mit starker Asymmetrie jedoch darauf hin, dass solche Asymmetrie

Communicated by A. Hedenström.

Extended author information available on the last page of the article 
stark durch die Selektion für aerodynamische Effizienz begrenzt ist, da Handschwingen-Asymmetrie die aerodynamische Stabilität, die Energiekosten des Startens, die Manövrierfähigkeit und die Agilität von Vögeln mit Schlagflug beeinflusst.

\section{Introduction}

Moulting of flight feathers is one of the most important processes in the avian annual cycle (Kjellén 1994; Barta et al. 2008). It incurs not only costs of feather synthesis, but also energetic expenses associated with increased flight costs as a consequence of gaps in wing area and increased predation risk due to lower manoeuvrability (Lindström et al. 1993; Swaddle et al. 1999; Lind 2001). As moult-related feather gaps seriously hinder flight performance and also increase flight metabolism (Tucker 1991; Chai 1997; Hedenström and Sunada 1999; Kiat et al. 2016), the cost of a decrease in wing area interplays with the timing of major annual life cycle events, such as migration and breeding (Kiat et al. 2016). Therefore, moulting strategies, and particularly the primary moult, are often investigated in studies on life history and trade-offs, due to their interactions with environmental conditions (De la Hera et al. 2009; Remisiewicz et al. 2009; Rohwer et al. 2011; Barshep et al. 2013).

Variations in the seasonality of food supply on breeding and wintering grounds drive the timing of flight feather moult with respect to migration (Barta et al. 2008). The majority of small and medium-sized migratory birds moult flight feathers after breeding before their autumn migration, or after migration on the wintering grounds. Some species begin the primary moult on the breeding grounds, suspend it during migration and complete the process on the wintering grounds, whereas others replace all primaries during the post-migration period (Cramp and Simmons 1986; Jenni and Winkler 1994; Holmgren and Hedenström 1995; Barta et al. 2008). As both the flight feather moult and breeding are energy-demanding processes, the overlap between them is costly (Holmgren and Hedenström 1995; Hemborg and Lundberg 1998). Hence, such an overlap is quite rare, and in waders breeding in the Northern Hemisphere it has only been found in short- or medium-distance migrants (Pienkowski et al. 1976; Walters 1984). Although a moult-breeding overlap leads to costs, it may also be an adaptive strategy (Barta et al. 2006; Bridge 2006; Morales et al. 2007).

Asymmetry during the primary moult has been described both in wild (Rasmussen 1988; Polo and Carrascal 1999; Hall and Franson 2001; Freed and Cann 2012; Zuberogoitia et al. 2013) and captive, non-manipulated birds (Mallet-Rodrigues 2012). As the moult takes place simultaneously on both wings, asymmetry in moulting of corresponding feathers on the right and left wings, defined as a random deviation from perfect symmetry in bilateral traits, may be used in studies on fluctuating asymmetry (Palmer 1994). It is widely accepted that fluctuating asymmetry reflects an animal's ability to cope with the sum of challenges that affect it during the growth period (Palmer and Strobeck 1986; Møller and Swaddle 1997). Primaries and other large feathers are suitable morphological traits for the study of fluctuating asymmetry, since they are replaced regularly and their morphogenesis may be studied under different environmental pressures (Polo and Carrascal 1999; Aparicio and Bonal 2002). Although much emphasis has been put on evaluating the influence of food limitation or ectoparasitism on the extent of asymmetry in flight feathers and how such asymmetry affects flight performance (e.g. Brown and Brown 1998; Swaddle and Witter 1994, 1998; Hambly et al. 2004), studies on species that replace primaries during migration are scarce and concern individuals with an interrupted moult (Hall and Franson 2001), or describe asymmetry in the moult pattern in individual birds (Cannell et al. 1983).

The Dunlin Calidris alpina is one of very few wader species that moults primaries when migrating towards its wintering grounds (Gromadzka 1989). Numerous birds from nominative subspecies that pass through the Baltic region in autumn originate from the vast area between Scandinavia and Central Siberia (Gromadzka 1985; Gromadzka and Ryabitsev 1998) up to the Taimyr Peninsula (Soloviev et al. 2012). Individuals at all stages of primary feather replacement are found among these birds (Gromadzka 1989; Holmgren et al. 1993), which makes this species a perfect choice for studies on the extent of fluctuating asymmetry in primaries growing during migration. Moreover, Dunlins in their second calendar year of life (immatures) migrate to their breeding grounds, which is rare among Arctic waders (Soikkeli 1967; Gratto and Morrison 1981; Hockey et al. 1998; Tavera et al. 2016). This provides an opportunity to search for age- and sexdependent differences in many aspects of their migratory behaviour.

In this study, we examined whether the occurrence and extent of asymmetry in the primary moult might be linked to age, sex, moult advancement, day of the season or amount of energetic reserves in Dunlins migrating through the southern Baltic towards their wintering grounds. We hypothesize that the extent of asymmetry may reflect the overlap of energetically costly activities such as breeding, migration and primary moult. From this hypothesis we predict that moult asymmetry may be strongly constrained 
by selection for aerodynamic efficiency, which is crucial for birds during migration; as a consequence of this, large asymmetry should be avoided.

\section{Methods}

\section{Bird catching}

Dunlins were caught using walk-in traps (Busse and Meissner 2015) at the mouth of the Vistula River on the Baltic coast of Poland $\left(54^{\circ} 21^{\prime} \mathrm{N}, 18^{\circ} 57^{\prime} \mathrm{E}\right)$ between 2009 and 2015. Each year, daily trapping started around 10 July and finished around mid-September. This period covers almost the whole migration of non-juvenile Dunlins in this area (Meissner and Sikora 1995; Meissner et al. 2009).

Wing length (rule with an accuracy of $1 \mathrm{~mm}$ ), total head length and bill length (callipers with an accuracy of $0.1 \mathrm{~mm}$ ) of each trapped Dunlin were measured (Busse and Meissner 2015). Birds were also weighed with an electronic balance with an accuracy of $1 \mathrm{~g}$. The age of captured birds was determined according to the description given by Meissner and Skakuj (2009), which allows distinguishing two age classes among non-juvenile Dunlins: immatures (birds in the second calendar year) and adults (older than 2 years). The group of 515 birds that could not be aged due to the lack of diagnostic feathers was excluded from the analyses. Dunlins were sexed according to a discriminant function based on the bill and wing lengths derived for birds older than 1 year migrating through the Baltic (Meissner and Pilacka 2008). In total, data on 7729 Dunlins were analysed in this study, including 3294 immatures and 4435 adults. Division of the time period into successive 10-day periods followed Berthold (1973).

\section{Moult scoring}

In the field, we used a standard moult formula, where the moult stage for each of ten primaries of both wings was recorded as a score between 0 (old feather) and 5 (new, full grown feather) (Ashmole 1962). The sum of moult scores for each of ten primaries on one wing of each bird gave the primary moult score (PMS), ranging from 0 (moult had yet to begin) to 50 (moult completed). These scores from both wings were summed and used as an index of primary moult advancement (IPMA), where 0 indicates a bird that has not yet started primary moult and 100 indicates a bird that has finished the primary moult in both wings. To transform the distribution of PMSs to a linear form, the standard moult formula of each bird was transformed into the proportion of feather mass grown (PFMG), where feathers that had moult scores of 1,2,3, 4 and 5 were given a corresponding moult index of $0.125,0.375,0.625,0.875$ and 1 , respectively, to represent the proportion of feather mass grown (Underhill and Summers 1993). The mean relative mass of each primary, which is needed for this transformation, was calculated from feathers dried to constant mass, obtained from three birds found dead near the study area (Table 1). Due to the small intraspecific variation in relative masses of primaries (Underhill and Joubert 1995), a sample of three sets of primaries was sufficient, especially given that the coefficient of variation in each case was not greater than $3 \%$. The absolute difference between PFMG of the left and right wing was used as an index of primary moult asymmetry.

To check if asymmetry in the primary moult is related to the amount of energetic stores, the scaled mass index (SMI) (Peig and Green 2009) was used as a proxy of body condition. It was calculated as:

$\mathrm{SMI}=\mathrm{BM}\left[\frac{\mathrm{BL}_{0}}{\mathrm{BL}}\right]^{b}$

where $\mathrm{BM}$ and $\mathrm{BL}$ are body mass and bill length of an individual, $\mathrm{BL}_{0}$ is the arithmetic mean value of bill length of the whole Dunlin sample and $b$ is the scaling exponent estimated from the standardized major axis regression of body mass and bill length calculated by dividing the slope of the ordinary linear square regression of $\operatorname{lnBM}$ and $\operatorname{lnBL}$ by Pearson's correlation coefficient (Peig and Green 2009). Among all linear body measurements, we used bill length, because it is the best predictor of the overall body size in Dunlins (Davidson 1983; Goede and Nieboer 1983; Piersma and van Brederode 1990).

\section{Statistical analysis}

A general linear model (GLM) was applied to check for the differences in primary moult advancement between immatures and adults, and in the following 10-day periods. We
Table 1 Mean relative mass (\%) of primaries of two adult and one juvenile Dunlin found dead in the mouth of the Vistula in autumn

\begin{tabular}{lllllllllll}
\hline Primary no. & 1 & 2 & 3 & 4 & 5 & 6 & 7 & 8 & 9 & 10 \\
\hline Mean & 4.22 & 4.80 & 5.76 & 6.82 & 8.46 & 10.18 & 11.76 & 13.78 & 15.74 & 18.48 \\
SD & 0.129 & 0.126 & 0.183 & 0.126 & 0.171 & 0.129 & 0.058 & 0.310 & 0.096 & 0.486 \\
CV & 2.3 & 2.4 & 2.6 & 2.2 & 2.4 & 1.0 & 0.5 & 2.8 & 0.6 & 3.0 \\
\hline
\end{tabular}

Primaries were numbered from the innermost to outermost $C V$ Coefficient of variation 
used a generalised linear model (GLZ) with binomial distribution and logit link function or logarithm link function and normal error distribution (McCullagh and Nelder 1983) to account simultaneously for the effects of all independent variables on the occurrence of asymmetrical primary moult and the index of primary moult asymmetry, respectively. In this analysis, only birds with asymmetrical moult (the index of primary moult asymmetry greater than 0 ) were taken into account. Dependent variables in GLZ analyses were related separately to sex, age, date of capture (day number in a year), an index of primary moult advancement and SMI. The Wald $\chi^{2}$-statistic was used to test for significant differences between groups. A stepwise backward selection was applied to include significant variables $(p<0.05)$ in the model. All statistical procedures were performed using Statistica 12 software (StatSoft 2014).

\section{Results}

Between the first half of July and the second half of August, the proportion of individuals in active primary moult increased from 33 to $94 \%$ in immatures and from 8 to $32 \%$ in adults (Fig. 1). In total, $68.2 \%$ of immatures moulted primaries, whereas only $26.6 \%$ of adults were in the primary moult.

In both age classes, the vast majority of birds had PFMG lower than $30 \%$ and only $2.1 \%$ of adults and $3.0 \%$ of immatures exceeded $50 \%$ of the grown primary feather mass (Fig. 2). Immatures were more advanced in the primary moult than adults (GLM, $F_{5,3403}=36.31, p<0.001$; Fig. 3), and the mean index of primary moult advancement increased in the following 10-day periods (GLM, $F_{5,3403}=113.89$, $p<0.001$; Fig. 3).

Data from all years were pooled, as we found no statistically significant differences between the proportion of individuals showing moult asymmetry among birds caught in subsequent years, either in immatures ( $G$-test, $G=4.24, d f=6, p=0.643$ ) or adults ( $G$-test, $G=9.96, d f=6$; $p=0.126$ ). Among birds moulting primaries, there were significantly more cases of asymmetrical moult in adults (37.7\% of 2248 individuals) than in immatures $(32.5 \%$ of 1178 individuals) ( $G$-test, $G=9.98, d f=1, p=0.003$ ).

Difference in PMS and PFMG between left and right wings did not differ significantly from zero either in adults or immatures (one-sample $t$-test, $p>0.252$ in all cases). Median difference in PMS between the left and right wing primaries was two points and $2.9 \%$ in PFMG. In a few extreme cases, these differences reached from ten to 15 points (seven individuals) and $12-20 \%$ in PMS and PFMG (14 individuals), respectively (Fig. 4). About $34 \%$ of birds revealed only a slightly asymmetrical primary moult (one-point difference in PMS between both wings), whereas half of them showed
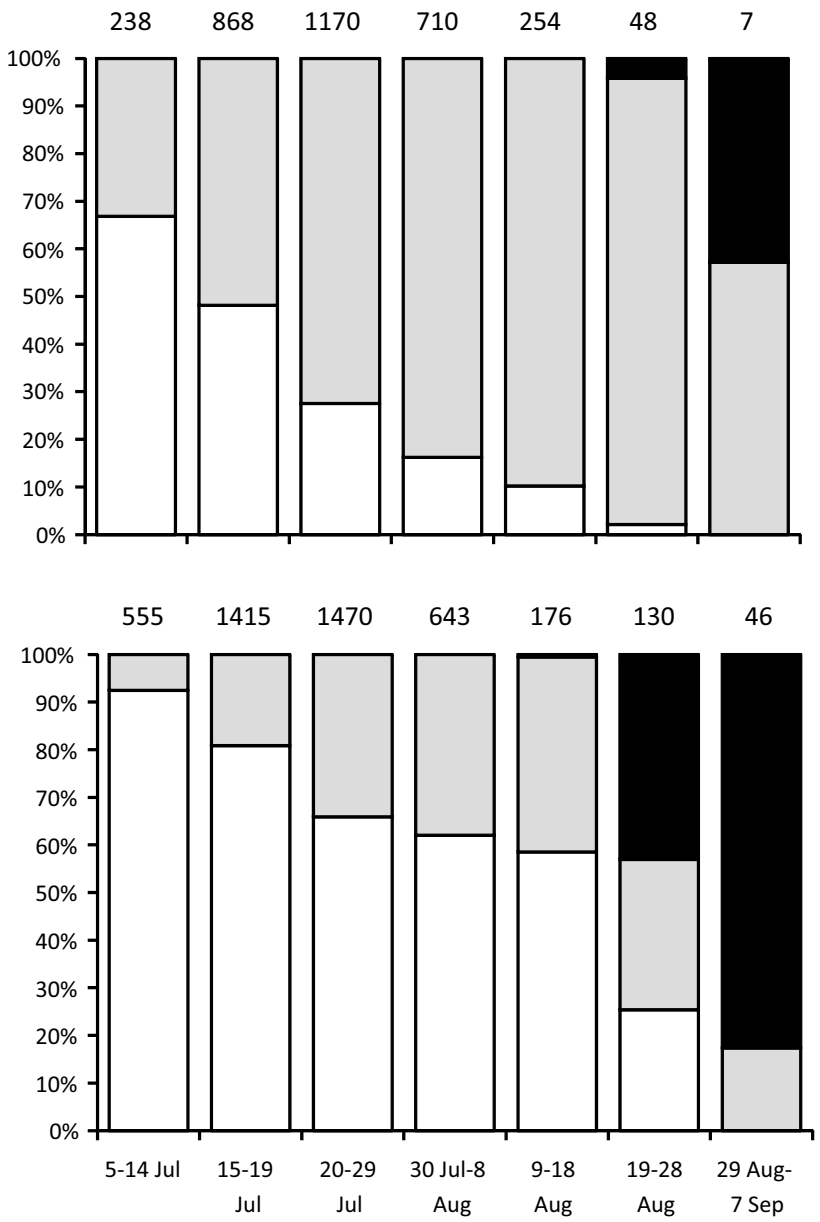

Fig. 1 Percentage of Dunlins at different primary moult stages. White Birds that have not yet started primary moult, grey birds in primary moult, black birds with all new primaries (moult finished in both wings). Top Immatures, bottom adults. Sample sizes are given above the bars

a difference of less than two PMS points. When taking into account PFMG, 13\% of Dunlins showed a difference between the left and right wing that was not greater than $1 \%$, and $50 \%$ of individuals showed a difference between the two wings that was lower than $3 \%$ of the total mass of primaries.

Among all independent variables, only day number in a year and the index of primary moult advancement had significant influences on the occurrence of moult asymmetry. The probability of asymmetry in the primary moult increased over time and decreased with the advancement of the moult (Table 2). Sex and age of birds had no significant effects on the occurrence of moult asymmetry (efficient score statistics from stepwise GLZ were 0.020 and 0.195 for sex and age, respectively, and $p>0.66$ in both cases).

The backward stepwise GLZ procedure selected a model with the day number in a year, index of moult advancement, sex and age, which had a significant influence on the IPMA. The asymmetry in the primary moult 

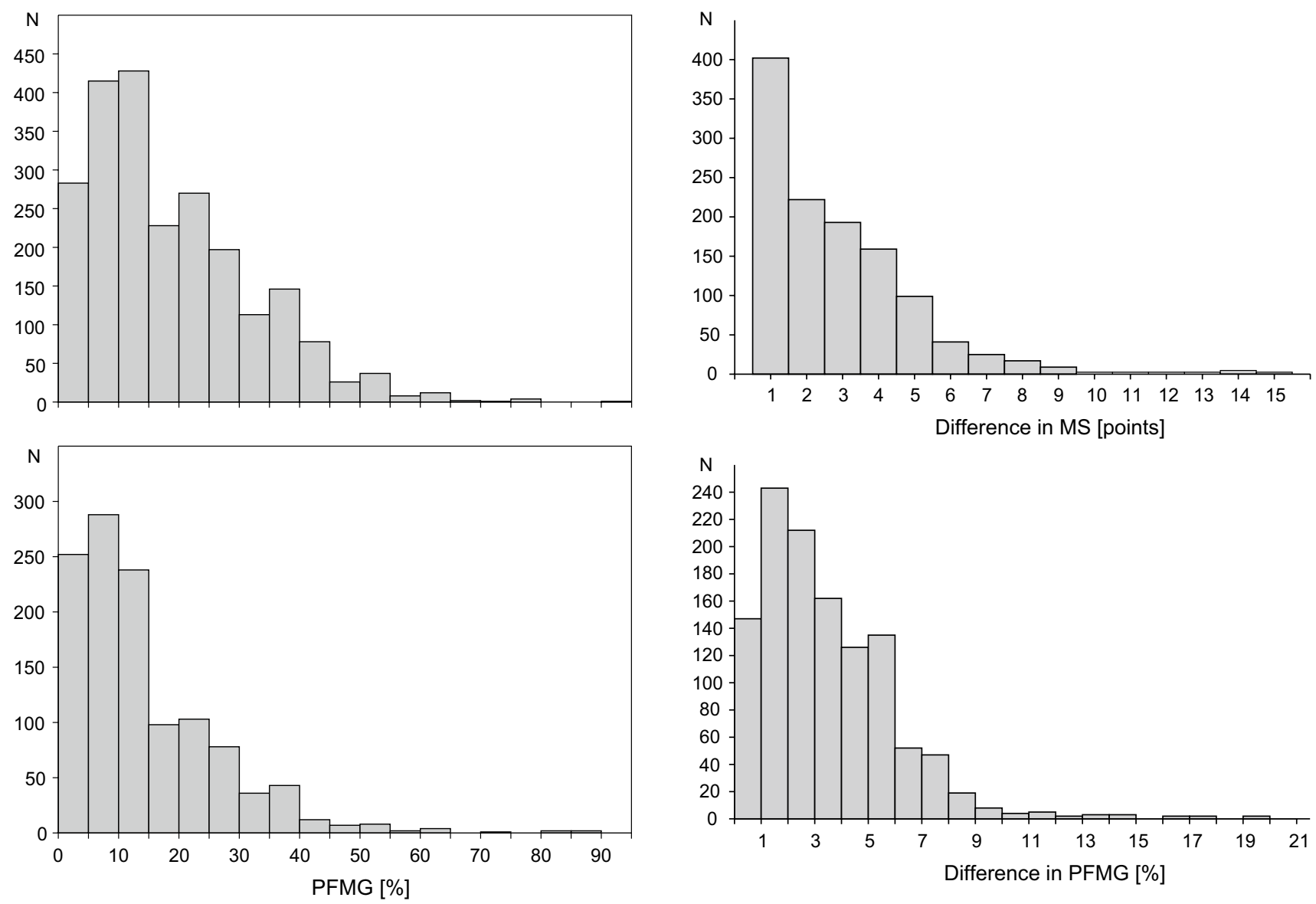

Fig. 2 Distribution of mean primary feather mass grown (PFMG) for both wings in immature (top) and adult (bottom) Dunlins

Fig. 4 Distribution of differences in primary moult scores (MS; top) and primary feathers mass grown (PFMG; bottom) between left and right wings of Dunlins showing asymmetrical moult (both age groups combined)

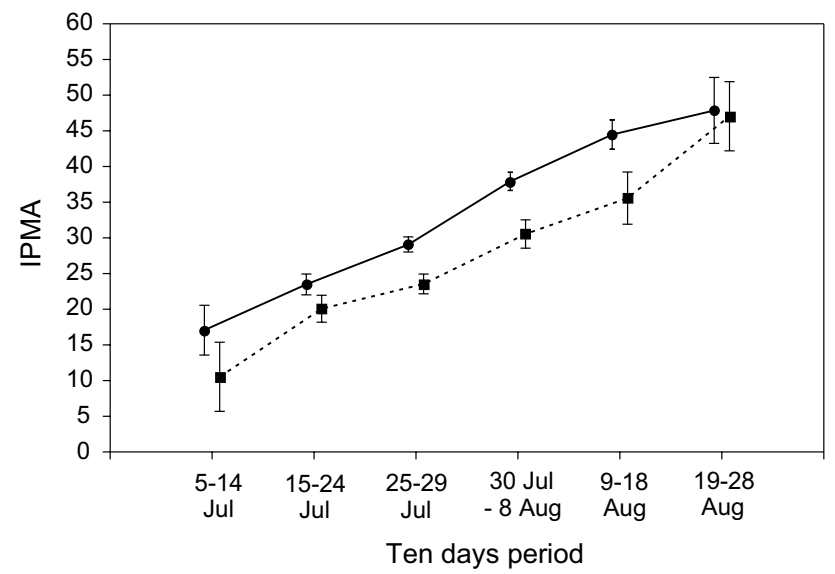

Table 2 Selected generalised linear model (GLZ) model with binomial distribution and logit link function for the occurrence of asymmetrical primary moult in Dunlins as the response variable and day number in a year (Day) and index of primary moult advancement as covariates

\begin{tabular}{lrlrl}
\hline Explanatory variable & Coefficient & SE & Wald $\chi^{2}$ & $p$ \\
\hline Constant & -4.376 & 0.819 & 28.58 & $<0.0001$ \\
Day & 0.022 & 0.004 & 29.29 & $<0.0001$ \\
Index of moult advancement & -0.031 & 0.002 & 178.84 & $<0.0001$ \\
\hline
\end{tabular}

Fig. 3 Mean index of primary moult advancement (IPMA) of immature (dots, solid line) and adult (squares, dashed line) Dunlins in the following 10-day periods. Only birds undergoing active primary moult were taken into account. Whiskers show $95 \%$ confidence interval. Data from the period after 28 August were omitted due to small sample size

increased in the following days of autumn migration and with the advancement of the primary moult. Also, the mean IPMA was lower in immature Dunlins than in adults, and in females compared to males (Table 3 ). Finally, no significant interaction was found between age and sex in the GLZ model (GLZ, Wald statistic $=1.64$, $p=0.20$ ). 
Table 3 Effects of day number in a year (Day), index of primary moult advancement (IPMA), age and sex on index of primary moult asymmetry among Dunlins captured in Puck Bay during autumn migration, according to the selected GLZ model

\begin{tabular}{lclrr}
\hline Explanatory variable & Coefficient & SE & Wald $\chi^{2}$ & \multicolumn{1}{l}{$p$} \\
\hline Constant & -4.721 & 0.458 & 106.09 & $<0.0001$ \\
Day & 0.006 & 0.002 & 6.21 & 0.0127 \\
IPMA & 0.007 & 0.001 & 27.70 & $<0.0001$ \\
Age (immature) & -0.058 & 0.021 & 7.43 & 0.0064 \\
Sex (female) & -0.059 & 0.022 & 6.96 & 0.0083 \\
\hline
\end{tabular}

Estimated regression coefficients are set to zero for baseline categories of categorical variables (age — adult, sex-male)

\section{Discussion}

Asymmetry in primaries affects aerodynamic stability and thus flight efficiency, take-off cost, manoeuvrability and agility in birds with flapping flight (Thomas 1993; Swaddle 1997; Swaddle and Witter 1998). That is why asymmetry in primaries, which are used for propulsion during flight, is always lower than in secondaries or rectrices (Stiles 1995; Polo and Carrascal 1999; Brommer et al. 2003; Arroyo et al. 2004), and migratory birds have more symmetrical wings than others (Balmford et al. 1993). Indeed, half of Dunlins with an asymmetrical primary moult had slight differences between both wings that were not greater than two PMS points and not greater than $3 \%$ of PFMG. This suggests that the extent of fluctuating asymmetry in the primary moult of migrating Dunlins could be strongly constrained, e.g. by selection for aerodynamic efficiency, and thus possibly represents a fitness cost to birds passing the southern Baltic, as asymmetry in primaries may reduce the probability of survival, as shown in the Ural Owl Strix uralensis and Cliff Swallow Petrochelidon pyrrhonota (Brown and Brown 1998; Brommer et al. 2003).

Deviations from bilateral symmetry correlate with fitness differences and are treated as indicators of environmental stress (Møller and Swaddle 1997). It is widely accepted that actual environmental conditions, particularly food limitation during the growth period, may disturb the process of feather synthesis and consequently affect the level of asymmetry of growing feathers (Swaddle and Witter 1994; Møller 1996; Freed and Cann 2012). In general, individuals that are in worse body condition or are nutritionally stressed show higher levels of asymmetry, especially in traits directly affecting locomotion (Thomas 1993; Swaddle and Witter 1994; Polo and Carrascal 1999; Nosil and Reimchen 2001). However, in this study, we found no relationship between a proxy of body condition (scaled mass index) and the index of primary moult asymmetry. It should be borne in mind that sandy coasts of the southern Baltic do not offer good feeding conditions for waders due to the lack of tides (Kube
1994; Meissner 2007) and that the vast majority of non-juvenile arctic waders stopping here arrive with low energetic reserves, usually remain for a few days only and reveal only a slight body mass increase during this time (Meissner 1998, 2007; Meissner and Górecki 2006). Moreover, very few individuals are retrapped in subsequent migratory seasons (Waterbird Research Group KULING, unpublished data), which suggests that the Gulf of Gdańsk is an emergency feeding site for these birds rather than a regular stopover.

The rough estimation of primary moult duration in Dunlin populations breeding in Siberia east of the Yamal Peninsula is about 48 days, and the mean mass growth of primaries was estimated as $2.08 \%$ of primary mass per day (Holmgren et al. 2001). Hence, birds that started to moult before their arrival at the study area must have commenced this on the breeding ground or during the first stage of their autumn migration. Data from museum skins analysed by Greenwood (1983) and Gromadzka (1989), as well as data from birds caught on nests in different parts of Eurasian breeding areas of the Dunlin (Kania 1990; Holmgren et al. 2001), indicate that only birds breeding east of the Ural Mountains initiate their primary moult when incubating eggs. The residence time of non-juvenile Dunlins in Siberian breeding areas after chick rearing remains unknown, but the timing and dynamics of their migration in Baydaratskaya Bay (southern Yamal Peninsula) and in the Baltic are very similar, with a migration peak of non-juvenile birds being only 5-6 days later in the Gulf of Gdańsk (southern Baltic) than in Yamal (Chernichko et al. 1998; Meissner and Strzałkowska 2006). This suggests that these birds depart from the breeding grounds shortly after breeding. Hence, in moulting birds caught in the study area, the causes of asymmetry in the primary moult were probably mostly connected with conditions on the breeding grounds rather than those at the previous stopover sites.

In Dunlins on east European and Siberian breeding grounds, there is a clear tendency for increasing the overlap of the primary moult with egg incubation and chick attendance with latitude and longitude (Holmgren et al. 2001). As metabolisable energy requirements increase during the moult (Lustik 1970; Dietz et al. 1992; Hoye and Buttemer 2011), overlapping the primary moult with other energetically expensive activities, such as migration, is expected to result in significant trade-offs in energy allocation. Moreover, migratory birds have less time for moulting than sedentary birds and are forced to produce feathers faster (Jenni and Winkler 1994; Kjellén 1994), which may increase the level of physiological stress. Hence, it is supposed that birds from more eastern and northern parts of this vast breeding area, which started to breed and hence migrated towards the wintering grounds later in the season, revealed higher stress levels because they started the primary moult during incubation and continue this when rearing chicks (Gromadzka 1989; Holmgren et al. 2001). 
Indeed in our study, the proportion of Dunlins showing an active primary moult increased throughout the season, and the index of primary moult asymmetry increased in the following days of the migration period and was greater in birds more advanced in primary replacement. A higher proportion of Common Whitethroats Sylvia communis with an asymmetrical number of newly grown primaries was recorded in the later part of the migration season, which was suggested to be a result of a high metabolic rate caused by the stress of moulting late in the season (Hall and Franson 2001). However, it should be remembered that the mass of primaries increases gradually from the innermost to the outermost feather and that P10 has over four times greater relative mass that P1 (see Table 1). The growth rate across primaries in waders seems to be similar (see Remisiewicz 2011 for a review), hence the progress through subsequent growth stages of an innermost primary seems to be four times faster than that of the outermost one, and this may an influence on the differences in scores between the inner and outer primaries. On the other hand, the probability of asymmetry in the primary moult in Dunlins decreased as the moult advanced (i.e. towards more outer primaries). Moreover, in Dunlins, the gap in the wing area due to not fully grown feathers generally decreased in later stages of the moult (Holmgren et al. 1993). It should be noted that the vast majority of Dunlins migrating through the Baltic during their active primary moult usually have no more than five or six new primaries (Holmgren et al. 1993; authors' unpublished data), so they are in the middle stage of primary replacement. All these findings suggest that birds avoid asymmetry, especially in the middle part of the wing, as this has a larger effect on increasing the energetic cost of flight than more distal gaps (Hedenström and Sunada 1999).

In the Dunlin, females attend broods for less time than males and usually depart during the first 10-12 days after the hatch (Soikkeli 1967; Jamieson 2011). Immatures that breed for the first time are less involved in breeding activities because they have a higher number of breeding failures than older, more experienced birds, and usually depart from the breeding grounds earlier (Meissner 2015). Hence, the higher index of primary moult asymmetry in adults than in immatures documented in this study, and in males compared to females, may reflect higher stress levels due to the longer period of involvement in breeding activities and consequently the longer overlap between the moult and breeding.

It seems that the extent of asymmetry in the primary moult in migrating Dunlins reflects the overlap of energetically costly activities such as breeding, migrating and flight feather replacement. The sex (males) and age class (adults) that spend more time on the breeding grounds revealed a higher index of primary moult asymmetry, most probably as a result of higher levels of physiological stress. However, the low proportion of birds with large asymmetry suggests that such asymmetry is related to some costs that, generally, are avoided.

Acknowledgements We thank all volunteers and ringers working at the ringing station of Waterbird Research Group KULING at the mouth of the Vistula, especially to M. Remisiewicz, M. Polak, P. Rydzkowski, S. Bzoma, L. Pilacka, P. Nagórski and M. Polakowski. Special thanks to Agnieszka Ożarowska for her comments on an earlier version of the manuscript. This is Waterbird Research Group KULING contribution no. 158 .

\section{Compliance with ethical standards}

Conflict of interest The authors declare that they have no conflict of interest.

Ethical approval All applicable international, national, and/or institutional guidelines for the care and use of animals were followed.

Open Access This article is distributed under the terms of the Creative Commons Attribution 4.0 International License (http://creativeco mmons.org/licenses/by/4.0/), which permits unrestricted use, distribution, and reproduction in any medium, provided you give appropriate credit to the original author(s) and the source, provide a link to the Creative Commons license, and indicate if changes were made.

\section{References}

Aparicio JM, Bonal R (2002) Why do some traits show higher fluctuating asymmetry than others? A test of hypotheses with tail feathers of birds. Heredity 89:139-144

Arroyo B, Mínguez E, Palomares L, Pinilla J (2004) The timing and pattern of moult of flight feathers of European Storm-petrel Hydrobates pelagicus in Atlantic and Mediterranean breeding areas. Ardeola 51:365-373

Ashmole NP (1962) The Black Noddy Anous tenuirostris on Ascension Island. Part I. General biology. Ibis 103:235-273

Balmford A, Jones IL, Thomas ALR (1993) On avian asymmetry: evidence of natural selection for symmetrical tails and wings in birds. Proc R Soc Lond B 252:245-251

Barshep Y, Minton CDT, Underhill LG, Erni B, Tomkovich P (2013) Flexibility and constraints in the molt schedule of long-distance migratory shorebirds: causes and consequences. Ecol Evol 3:1967-1976

Barta Z, Houston AI, McNamara JM, Welham RK, Hedenström A, Weber TP, Feró O (2006) Annual routines of non-migratory birds: optimal moult strategies. Oikos 112:580-593

Barta Z, McNamara JM, Houston AI, Weber TP, Hedenström A, Feró O (2008) Optimal moult strategies in migratory birds. Philos Trans R Soc B 363:211-229

Berthold P (1973) Proposals of standarization of the presentation of animal events, especially migratory data. Auspicium 5 suppl:49-57

Bridge ES (2006) Influences of morphology and behavior on wing-molt strategies in seabirds. Mar Ornithol 34:7-19

Brommer JE, Pihlajamäki O, Kolunen H, Pietiäinen H (2003) Lifehistory consequences of partial-moult asymmetry. J Anim Ecol 72:1057-1063 
Brown CR, Brown MB (1998) Intense natural selection on body size and wing and tail asymmetry in Cliff Swallows during severe weather. Evolution 52:1461-1475

Busse P, Meissner W (2015) Bird ringing station manual. De Gruyter Open, Berlin

Cannell PF, Cherry JD, Parkes KC (1983) Variation and migration overlap in flight feather molt of the Rose-breasted Grosbeak. Wilson Bull 95:621-627

Chai P (1997) Hummingbird hovering energetics during moult of primary flight feathers. J Exp Biol 200:1527-1536

Chernichko JI, Gromadzki M, Diadicheva EA, Grinchenko AB (1998) Post-breeding gatherings and migration of waders on the eastern coast of Baydaratskaya Bay. Branta 1:79-91

Cramp S, Simmons KEL (eds) (1986) The birds of the western Palearctic, vol 3. Oxford University Press, Oxford

Davidson NC (1983) Formulae for estimating the lean weight and fat reserves of live shorebirds. Ringing Migr 5:49-64

De la Hera I, Pérez-Tris J, Tellería JL (2009) Migratory behaviour affects the trade-off between feather growth rate and feather quality in a passerine bird. Biol J Linn Soc 97:98-105

Dietz MW, Daan S, Masman D (1992) Energy requirements for molt in the Kestrel Falco tinnunculus. Physiol Zool 65:1217-1235

Freed LA, Cann RL (2012) Changes in timing, duration, and symmetry of molt of Hawaiian forest birds. PLoS ONE 7:e29834

Goede AA, Nieboer E (1983) Weight variation of Dunlins Calidris alpina during post-nuptial moult, after application of weight data transformations. Bird Study 30:157-163

Gratto CL, Morrison RIG (1981) Partial postjuvenile wing moult of the Semipalmated Sandpiper Calidris pusilla. Wader Study Group Bull 33:33-37

Greenwood JG (1983) Post-nuptial primary moult in Dunlin Calidris alpina. Ibis 125:223-228

Gromadzka J (1985) Dunlin-Calidris alpina (L.). In: Viksne IA, Mihelson HA (eds) Migrations of birds of eastern Europe and northern Asia. Gruiformes-Charadriiformes. Nauka, Moscow, pp 193-220 (in Russian)

Gromadzka J (1989) Breeding and wintering areas of Dunlin migrating through southern Baltic. Ornis Scand 20:132-144

Gromadzka J, Ryabitsev VK (1998) Siberian Dunlins Calidris alpina migrate to Europe: first evidence from ringing. Int Wader Stud 10:88-90

Hall KSS, Franson T (2001) Wing moult in relation to autumn migration in adult Common Whitethroats Sylvia communis communis. Ibis 143:580-586

Hambly C, Harper EJ, Speakman JR (2004) The energetic cost of variations in wing span and wing asymmetry in the Zebra Finch Taeniopygia guttata. J Exp Biol 207:3977-3984

Hedenström A, Sunada S (1999) On the aerodynamics of moult gaps in birds. J Exp BioI 202:67-76

Hemborg C, Lundberg A (1998) Costs of overlapping reproduction and moult in passerine birds: an experiment with the Pied Flycatcher. Behav Ecol Sociobiol 43:19-23

Hockey PAR, Turpie JK, Velásquez CR (1998) What selective pressures have driven the evolution of deferred northward migration by juvenile waders? J Avian Biol 29:325-330

Holmgren N, Hedenström A (1995) The scheduling of molt in migratory birds. Evol Ecol 9:354-368

Holmgren N, Ellegren H, Pettersson J (1993) The adaptation of moult pattern in migratory Dunlins Calidris alpina. Ornis Scand 24:21-27

Holmgren NMA, Jönsson PE, Wennerberg L (2001) Geographical variation in the timing of breeding and moult in Dunlin Calidris alpina on the Palearctic tundra. Polar Biol 24:369-377

Hoye BJ, Buttemer WA (2011) Inexplicable inefficiency of avian molt? Insights from an opportunistically breeding arid-zone species, Lichenostomus penicillatus. PLoS One 6:e16230
Jamieson SE (2011) Pacific Dunlin Calidris alpina pacifica show a high propensity for second clutch production. J Ornithol 152:1013-1021

Jenni L, Winkler R (1994) Moult and aging of European passerines. Academic Press, London

Kania W (1990) The primary moult of breeding Dunlins Calidris alpina in the central Taymyr in 1989. Wader Study Group Bull 60:17-19

Kiat Y, Izhaki I, Sapir N (2016) Determinants of wing-feather moult speed in songbirds. Evol Ecol 30:783-795

Kjellén N (1994) Moult in relation to migration in birds-a review. Ornis Svec 4:1-24

Kube J (1994) Aspekte der Nahrungsökologie ziehender Limikolen an der südlichen Ostseeküste. Corax 15. Sonderheft 2:57-72

Lind J (2001) Escape flight in moulting Tree Sparrows (Passer montanus). Funct Ecol 15:29-35

Lindström A, Visser GH, Daan S (1993) The energetic cost of feather synthesis is proportional to basal metabolic rate. Physiol Zool 66:490-510

Lustik K (1970) Energy requirements of molt in cowbirds. Auk $87: 742-746$

Mallet-Rodrigues F (2012) Replacement and growth of primary feathers in captive Rock Pigeons, Columba livia (Aves: Columbidae). Zoologia 29:121-125

McCullagh P, Nelder JA (1983) Generalized linear models. Chapman and Hall, London

Meissner W (1998) Fat reserves in Dunlins (Calidris alpina) during autumn migration through Gulf of Gdańsk. Ornis Svec 8:91-102

Meissner W (2007) Stopover strategy of adult and juvenile Red Knots Calidris c. canutus in the Puck Bay, southern Baltic. Ardea 95:97-104

Meissner W (2015) Immature Dunlins Calidris alpina migrate towards wintering grounds later than adults in years of low breeding success. J Ornithol 156:47-53

Meissner W, Górecki D (2006) Biometrics and body mass variation of Curlew Sandpiper Calidris ferruginea caught on the Puck Bay coast, Poland, during southward migration. Int Wader Stud 19:125-129

Meissner W, Pilacka L (2008) Sex identification of adult Dunlins Calidris alpina alpina migrating in autumn through Baltic region. Orn Fenn 85:135-138

Meissner W, Sikora A (1995) Spring and autumn migration of waders (Charadrii) on the Hel Peninsula. Not Orn 36:205-239 (in Polish with English summary)

Meissner W, Strzałkowska M (2006) Autumn migration dynamics of the Dunlin (Calidris alpina) at the Reda mouth (southern Baltic). Ring 28:33-43

Meissner W, Włodarczak-Komosińska A, Górecki D, Wójcik C, Ściborski M, Krupa R, Zięcik P, Kozakiewicz M, Rydzkowski P, Remisiewicz M (2009) Autumn migration of waders (Charadrii) at the Reda mouth (N Poland). Ring 31:23-39

Møller AP (1996) Development of fluctuating asymmetry in tail feathers of the Barn Swallow Hirundo rustica. J Evol Biol 9:677-694

Møller AP, Swaddle JP (1997) Asymmetry, developmental stability, and evolution. Oxford University Press, Oxford

Morales J, Juan Moreno J, Merino S, Sanz JJ, Tomás G, Arriero E, Lobato E, Martínez-De La Puente J (2007) Early moult improves local survival and reduces reproductive output in female Pied Flycatchers. Ecoscience 14:31-39

Nosil P, Reimchen TE (2001) Tarsal asymmetry, nutritional condition, and survival in Water Boatmen (Callicorixa vulnerata). Evolution $55: 712-720$

Palmer AR (1994) Fluctuating asymmetry analyses: a primer. In: Markow TA (ed) Developmental instability: its origins and evolutionary implications. Kluwer, Dordrecht, pp 335-364 
Palmer AR, Strobeck C (1986) Fluctuating asymmetry: measurement, analysis, patterns. Annu Rev Ecol Syst 17:391-421

Peig J, Green AJ (2009) New perspectives for estimating body condition from mass/length data: the scaled mass index as an alternative method. Oikos 118:1883-1891

Pienkowski MW, Knight PJ, Stanyard DJ, Argyle FB (1976) The primary moult of waders on the Atlantic coast of Morocco. Ibis 118:347-365

Piersma T, van Brederode NE (1990) The estimation of fat reserves in coastal waders before their departure from northwest Africa in spring. Ardea 78:221-236

Polo V, Carrascal LM (1999) Ptilochronology and fluctuating asymmetry in tail and wing feathers in Coal Tits Parus ater. Ardeola 46:195-204

Rasmussen PC (1988) Stepwise molt of remiges in Blue-eyed and King Shags. Condor 90:220-227

Remisiewicz M (2011) The flexibility of primary moult in relation to migration in Palaearctic waders - an overview. Wader Study Group Bull 118:141-152

Remisiewicz M, Tree AJ, Underhil LG, Gustowska A, Taylor PB (2009) Extended primary moult as an adaptation of adult Wood Sandpipers Tringa glareola to their use of freshwater habitats of southern Africa. Ardea 97:271-280

Rohwer S, Viggiano A, Marzluff JM (2011) Reciprocal tradeoffs between molt and breeding in albatrosses. Condor 113:61-70

Soikkeli N (1967) Breeding cycle and population dynamics in the Dunlin (Calidris alpina). Ann Zool Fenn 4:158-198

Soloviev MY, Tomkovich PS, Popovkina AB, Golovnyuk VV (2012) Recent advances in understanding migration links of waders (Charadrii) breeding on Taimyr Peninsula. Zool Zh 91:831-842 (in Russian)

StatSoft (2014) Statistica (data analysis software system), version 12. https://www.statsoft.com
Stiles FG (1995) Intraspecific and interspecific variation in molt patterns of some tropical hummingbirds. Auk 112:118-132

Swaddle JP (1997) Within-individual changes in developmental stability affect flight performance. Behav Ecol 8:601-604

Swaddle JP, Witter MS (1994) Food, feathers and fluctuating asymmetries. Proc R Soc Lond B 255:147-152

Swaddle JP, Witter MS (1998) Cluttered habitats reduce wing asymmetry and increase flight performance in European Starlings. Behav Ecol Sociobiol 42:281-287

Swaddle JP, Williams EV, Rayner JMV (1999) The effect of flight feather moult on escape take-off performance in starlings. J Avian Biol 30:351-358

Tavera EA, Lank DB, Gonzáles PM (2016) Effects of migration distance on life history strategies of Western and Semipalmated Sandpipers in Perú. J Field Ornithol 87:293-308

Thomas ALR (1993) The aerodynamic costs of asymmetry in the wings and tail of birds: asymmetric birds can't fly round tight corners. Proc R Soc Lond B 254:181-189

Tucker VA (1991) The effect of molting on the gliding performance of a Harris' Hawk (Parabuteo unicinctus). Auk 108:108-113

Underhill LG, Joubert A (1995) Relative masses of primary feathers. Ringing Migr 16:109-116

Underhill LG, Summers RW (1993) Relative masses of primary feathers in waders. Wader Study Group Bull 71:29-31

Walters J (1984) The onset of primary moult in breeding Charadrius Plovers. Bird Study 31:43-48

Zuberogoitia I, de la Puente J, Elorriaga J, Alonso R, Palomares LE, Martínez JE (2013) The flight feather molt of Griffon Vultures (Gyps fulvus) and associated biological consequences. J Raptor Res 47:292-303

\section{Affiliations}

\section{Włodzimierz Meissner ${ }^{1}$ (D) $\cdot$ Grzegorz Zaniewicz ${ }^{1} \cdot$ Andrzej Kośmicki $^{2}$. Anna Włodarczak-Komosińska ${ }^{3}$}

\section{Włodzimierz Meissner}

w.meissner@ug.edu.pl

1 Avian Ecophysiology Unit, Department of Vertebrate Ecology and Zoology, Faculty of Biology, University of Gdańsk, Wita Stwosza 59, 80-308 Gdańsk, Poland
2 Waterbird Research Group KULING, Kruczkowskiego 15c/9, 80-288 Gdańsk, Poland

3 Waterbird Research Group KULING, Popiełuszki 1/43, 10-693 Olsztyn, Poland 